\title{
Modeling the Exchange Rate of the Jordanian Dinar and US Dollar against the Israeli Sheikl
}

\author{
Abdalla M. EL-HABIL, (Ph.D.) \\ in Applied Statistics \\ Department of Applied Statistics, Faculty of Economics and \\ Administrative Sciences; Al-Azhar University, Gaza - Palestine. \\ abdalla20022002@yahoo.com
}

\begin{abstract}
In this empirical study, modeling the exchange rate of the Jordanian Dinar and US Dollar against the Israeli Sheikl is done by using the ARIMA and Transfer Function models. I demonstrated the importance of outlier detection and adjustment through the parameters significances and the moderate change in forecasted values. I come up with the conclusion that the transfer function forecasts better track the data as compared to the ARIMA forecasts. By this study, I added new empirical evidence on the important of transfer function modeling that is forward-looking. It will capture both the immediate and longer term effects of intervention.
\end{abstract}

$$
\begin{aligned}
& \text { نمذجة معدل سعر الصرف للاينار الأردني والدولار الأمريكي مقابل } \\
& \text { الشيكل الإسر ائيلي الأي } \\
& \text { الاكتور عبدالله الهبيل } \\
& \text { قسم الإحصاء التطبيقي }
\end{aligned}
$$

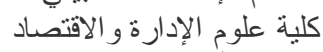

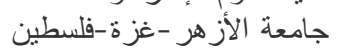

من خلال الار اسدة الحالية تم تطبيقق نمذجة معدل التغيّر في الدينار الأردذي و الذدولار

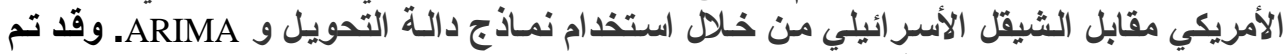

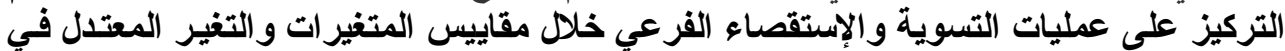

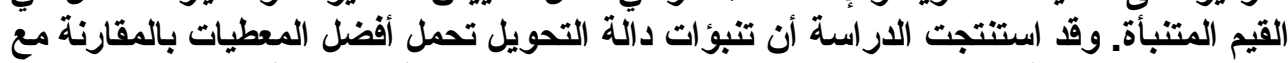

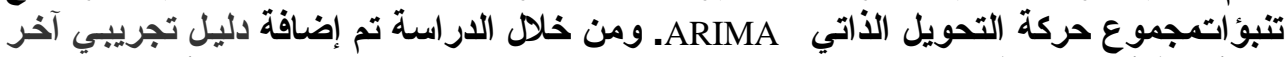

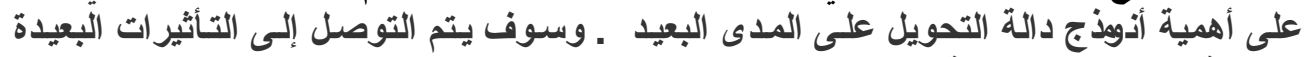
والآنية التي تثخلل العملية.

\section{Introduction}

In the analysis of a single time series, we basically limit our modeling to the information contained in the series own in past, and we do not explicitly use the information contained in other related stochastic time series. In

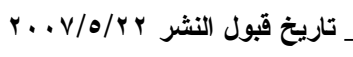

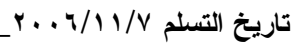


many cases, we may be able to connect the response (i.e., the observed value) of one series to its own past values, and also to the past and present values of other time series. In this manner, we effectively merge the basic concepts of the regression model with that of an Autoregressive Integrated Moving Average (ARIMA) models using class of models known as transfer function models. Transfer function models are flexible time series models that can be used for a variety of applications.

The paper is organized as follows:

Section 2 recalls the technical background of Transfer Function model. Section 3 presents the data.

Section 4 ARIMA and Transfer Function modeling and forecasting. Section 5 conclusions.

\section{The Transfer Function Model}

In many cases, we may able to connect the response (i.e., the observed value) of one series to its own past values, and also to the past and present values of other time series. So, we consider a time series $Y_{t}$ is an output time series, whose values may be related to one or more input time series $\mathrm{X}_{\mathrm{t}}$, for example, sales may be related to advertising expenditures; daily electricity consumption may be related to certain weather variable series such as maximum daily temperature or relative humidity or both.

For a single explanatory variable, the transfer function model is

$\mathrm{Y}_{\mathrm{t}}=\mathrm{C}+\mathrm{B}_{1} \mathrm{X}_{\mathrm{t}}+\mathrm{N}_{\mathrm{t}}$

where Yt represents a stationary ARMA process. If we assume that the input and output variables are both stationary time series, the general form of the single - input, single - output transfer function model can be expressed as:

$\mathrm{Y}_{\mathrm{t}}=\mathrm{C}+[\omega(\mathrm{B}) / \delta(\mathrm{B})] \mathrm{X}_{\mathrm{t}}+\mathrm{N}_{\mathrm{t}}$

where $\mathrm{N}_{\mathrm{t}}$ follows an ARMA model (i.e., $\mathrm{N}_{\mathrm{t}}=[\theta(\mathrm{B}) / \phi(\mathrm{B})]$ at)

and

$\omega(\mathrm{B})=\omega_{0}+\omega_{1}(\mathrm{~B})+\omega_{2}(\mathrm{~B}) * * 2+\ldots \ldots \ldots+\omega_{[\mathrm{s}-1]}(\mathrm{B}) * *[\mathrm{~s}-1]$

and $\delta(\mathrm{B})=1-\delta_{1}(\mathrm{~B})-\delta_{2}(\mathrm{~B}) * * 2-\ldots \ldots . .-\delta \mathrm{r}(\mathrm{B}) * * \mathrm{r}$.

Liu, L.-M., Hudak, G. B. (1992-2000).

Practically, the number of terms in $\omega(\mathrm{B})$ is small and the value for $r$ is usually 0 or 1 . We can also represent the rational polynomial operator $\omega(\mathrm{B}) / \delta(\mathrm{B})$ with a linear operator $v(\mathrm{~B})$, where $v(\mathrm{~B})=v_{0}+v_{1} \mathrm{~B}+$ $v_{2} \mathrm{~B} * * 2+$.

The polynomial operators are related according to $v(B)=\omega(B) / \delta(B)$

Since, we assume the transfer function is stable, the coefficients $v_{0}, v_{1}$, $v_{2}$, diminish to zero regardless the order of the $\delta(\mathrm{B})$ polynomial. If the linear operator $v(\mathrm{~B})$ is used, the model in (1) can be written as :

$\mathrm{Y}_{\mathrm{t}}=\mathrm{C}+\mathrm{v}(\mathrm{B}) \mathrm{X}_{\mathrm{t}}+\mathrm{N}_{\mathrm{t}}$ 
In the event that $\delta(B)=1$ (i.e., $r=0$ ), we have $v(B)=\omega(B)$ and $v(B)$ has a finite number of terms. In the case that $\delta(B) \neq 1$ (i.e., $r>0$ ), then $v(B)$ has an infinite number of terms.

The representation in (1) can be extended directly to the case of multiple - input transfer function model as:

$\mathrm{Y}_{\mathrm{t}}=\mathrm{C}+\left[\omega_{1}(\mathrm{~B}) / \delta_{1}(\mathrm{~B})\right] \mathrm{X}_{1 \mathrm{t}}+\ldots \ldots . .+\left[\omega_{\mathrm{m}}(\mathrm{B}) / \delta_{\mathrm{m}}(\mathrm{B})\right] \mathrm{X}_{\mathrm{m}} \mathrm{t}+\mathrm{N}_{\mathrm{t}}$

We can also use the linear form of the transfer function by writing (2) as:

$\mathrm{Y}_{\mathrm{t}}=\mathrm{C}+v_{1}(\mathrm{~B}) \mathrm{X}_{1 \mathrm{t}}+v_{2}(\mathrm{~B}) \mathrm{X}_{2 \mathrm{t}}+$ $.+v_{\mathrm{m}}(\mathrm{B}) \mathrm{X}_{\mathrm{mt}}+\mathrm{N}_{\mathrm{t}}$

The values $v_{0}, v_{1}, v_{2}, \ldots$ are either referred to as the transfer function weights or the impulse response weights for the input series $X_{t}$ (see chapter 9 of Box and Jenkins, 1970). These weights provide a measure of how the input series affects the output series, and the weight given to each time lag. That is $v 0$, is a measure of how the current response is affected by the current value of the input series; $v_{1}$ is a measure of how the current response is affected by the value of the input series one period ago; $v_{2}$ is a measure of how the current response is affected by the value of the input series two periods ago; and so on. The sum of all weights, usually represented by $\mathrm{g}$, is called the steady state gain and represents the total change in the mean level of the response variable if we maintain the input at a single unit increase above its mean level.

There are three assumptions of the model in (2) which describes the transfer function between $\mathrm{X}_{\mathrm{t}}$ and $\mathrm{Y}_{\mathrm{t}}$ (either in a linear form or as a rational polynomial):

1. The input series can affect the response variable, but not conversely (i.e., the relationship between $\mathrm{X}_{\mathrm{t}}$ and $\mathrm{Y}_{\mathrm{t}}$ is unidirectional).

2. The input series is assumed to be independent of the disturbance.

3. The model is stable; this is usually manifested by assuming the input and output series are stationary time series, and that the sum of the transfer function (TF) weights is finite.

The assumption that the output series do not affect the input series is often appropriate to the physical or engineering processes. In these cases, the input may be viewed as a controller mechanism that is used to maintain a certain level in the response variable. If we model the economic and business data, we may wish to use more dynamic models that allow for bi directional (or feedback) relationships. Examples of such models include simultaneous transfer function (STF) models, vector ARMA models. However, although the assumption of a unidirectional relationship may not be strictly true, transfer function models can still be effectively in modeling business and economic data.

Note: There are some special cases of the transfer function model shown in (3):

1. If there are no explanatory variables, then the transfer function is the ARIMA model. 
2. The intervention models can be obtained directly if all input series are binary series (that are, series consisting of only the values 0 and 1).

See Liu, L.-M., Hudak, G. B. (1992-2000).

\section{Data}

In Palestine, it is usually considered that the exchange rate of the US dollar against the Israeli Sheikl is as an indicator to the exchange rate of the Jordanian Dinar against the Israeli Sheikl. Since, these currencies mentioned have been locally used; I will use them in the analysis as a real data. The data consist of daily observations over the period from January 1, 2001 to September 25, 2001 (268 observations). The data are obtained from the website www.oanda.com.

On the basis of the plots of the two series, one can see that the dollar series appear to be a good indicator for the Dinar series as its "peaks", "valleys", and "turning points".

The input series (dollar series) can affect the response variable (Dinar series), but not conversely (i.e., the relationship between dollar and Dinar is unidirectional); and the input series (dollar series) is assumed to be independent of the disturbance.

However, although the assumption of a unidirectional relationship may not be strictly true, transfer function models can still be used effectively in modeling business and economic data [see Liu and Hudak (1992-2000), "Forecasting and time series analysis using the SCA statistical system", Volume 1].

I used only the first (244) observations for model building and estimation for both Dinar series alone and the transfer function model involving Dinar and Dollar series. The last (24) observations are retained to evaluate forecast performance, and to compare transfer function and Autoregressive Integrated Moving Average (ARIMA) results with actual values. Through the analysis, we have to check for outliers in the model, because outliers can have an important impact on an analysis.

\section{ARIMA Models for the Dinar and Dollar Time Series}

For an actually observed time series, Box and Jenkins (1970) have developed a three - stages iterative procedure for building ARIMA models to represent the data. The first step of this procedure is to specify tentative values of $\mathrm{p}, \mathrm{d}$, and $\mathrm{q}$ by examining the sample autocorrelations. Then, the estimates for parameters $\Phi$ 's and $\theta$ 's can be obtained by maximizing the likelihood function. After fitting the tentative model to the data, diagnostic checks are applied to the residuals to detect the possible inadequacy and diagnose the causes.

To build ARIMA models to describe the behaviors of time series, the assumption is made that the observations are homogeneously generated 
from the same probability structure. However, in practice, it often happens that a few of the observations appear to be so discordant with the remaining ones that the homogeneity assumption becomes doubtful. These discordant or aberrant observations are usually referred to as "outliers" in the literature. They may be caused simply by measurement or recording mistakes or by some non - repetitive exogenous interventions. For instance, economic and business time series are often subject to the influence of interventions like strikes, outbreak of wars, or a sudden change in the market structure of a commodity, etc. (See Box, G. E. P., and Tiao, G. C. (1975)).

On the plot of Dinar series, the Auto - Correlation Function (ACF) of Dinar decays exponentially, the Partial Auto-Correlation Function (PACF) cuts off after one lag, and the Extended Auto - Correlation Function (EACF) of Dinar series is considered. I concluded that the Autoregressive Integrated Moving Average (ARIMA) model for Dinar series is ARIMA $(1,0,2)$, it is found that the model fits the data, according to the results of the ACF of the residuals. When we used only the first 244 observations for model building of both the Dinar and the Dollar series, it is found that the model for the Dinar series is ARIMA $(1,0,2)$, and the model for the Dollar series is ARIMA $(1,0,1)$. These models have been fitted to the data, and it was noticed that the corresponding parameters are significant.

\section{Transfer Function Modeling}

I used the linear transfer function method (LTF) to identify a transfer function model. Since, there is no apparent seasonality in the data, we used an $\operatorname{AR}(1)$ approximation for the disturbance term $\left(\mathrm{N}_{\mathrm{t}}\right)$. We began the LTF method with $11 \mathrm{TF}$ weights (i.e., the 0th through 10th lags inclusive), the model was

dinar $\mathrm{t}=\mathrm{C}+[v 0+v 1 \mathrm{~B}+\ldots \ldots+v 10 \mathrm{~B} * * 10]$ dollar $\mathrm{t}+[1 /(1-\phi \mathrm{B})]$ at.

When we estimated the model, our attention is drawn immediately to estimate of the AR parameter. This value is approximately close to 1 . Hence, we may conclude that we should employ differencing to achieve stationarity. We also confirmed this by computing the ACF of the estimated disturbance, NT. It was found that it decays exponentially. So, we considered the model

$(1-\mathrm{B})$ dinar $\mathrm{t}=\mathrm{C}+[v 0+v 1 \mathrm{~B}+\ldots \ldots+v 10 \mathrm{~B} * * 10](1-\mathrm{B})$ dollar $\mathrm{t}+[1 /(1-\phi \mathrm{B})]$ at Or dinar $\mathrm{t}=\mathrm{C}+[v 0+v 1 \mathrm{~B}+\ldots \ldots+v 10 \mathrm{~B} * * 10]$ dollar $\mathrm{t}+[1 /(1-\phi \mathrm{B})(1-\mathrm{B})]$ at.

Since the transfer function weights for the input variable (dollar) cut-off after the contemporaneous lag, there is no need to incorporate the denominator polynomial $\delta(\mathrm{B})$ for the transfer function. Also when a set of estimated TF weights exhibits a die-out pattern, we can use the corner method to identify the orders in a corresponding rational transfer function, $\omega(\mathrm{B}) / \delta(\mathrm{B})$. Based on the corner method, we supported the idea that we don't need to incorporate the denominator polynomial $\delta(B)$. Also by examining 
the EACF of the disturbance term, it has been found that its model is ARIMA $(0,0,2)$. So, I considered the model

$(1-\mathrm{B})$ dinar $\mathrm{t}=\mathrm{C}+(\mathrm{v} 0)(1-\mathrm{B})$ dollar $\mathrm{t}+\left(1-\theta_{2} \mathrm{~B}^{2}\right)$ at

This model has been estimated and it found fit the data, since all sample autocorrelations of the residuals are found to within a $95 \%$ confidence limit of zero. This part of diagnostic checking reveals no model inadequacy. Also, I checked the adequacy of the proposed model using the Cross Correlation Function (CCF), which is a measure of association between the currently observed values (or residuals) of one series with the values of another series at current and prior time periods. It was found that there is no significant cross correlation between the residuals of the input series and the residuals of the transfer function model, except for those attributable to sample the variation. So, the input variable of the transfer function may be considered an independent variable of the disturbance. We may notice that the trend estimate (constant term) is insignificant, so we can delete it from the model. Therefore, our fitted transfer function model is

$(1-\mathrm{B})$ dinar $\mathrm{t}=(\mathrm{v} 0)(1-\mathrm{B})$ dollar $\mathrm{t}+\left(1-\theta_{2} \mathrm{~B}^{2}\right)$ at

So, we conclude that the exchange rate of Jordanian Dinar against the Israeli sheikl is influenced by the exchange rata of the US Dollar against the Israeli Sheikl contemporaneously.

On the basis of estimation of the transfer function model with outlier detection and adjustment, the model is:

$(1-\mathrm{B})$ dinar $\mathrm{t}=1.4276(1-\mathrm{B})$ dollar $\mathrm{t}+\left(1-0.452 \mathrm{~B}^{2}\right)$ at

From the estimation output with outlier detection and adjustment, the four major outliers detected at $\mathrm{t}=153$ (innovational outlier), $\mathrm{t}=155,237$ and 250 (level shift outliers) represent a dynamic level shift that might be caused by fluctuations in the exchange rate market.

Since, there has been a difference in the estimates of the transfer function model with and without outlier adjustment, it is the similar to the forecasted values, one can realize the importance of outlier detection and adjustment in time series modeling.

\section{Forecasting from the Transfer Function Model}

Values forecasted for the Dollar series are used to forecast the Dinar series. The last 24 observations for Dinar series are retained for a post sample check of forecasting performance. 


\begin{tabular}{|c|c|c|}
\hline \multicolumn{3}{|c|}{$\begin{array}{l}\text { Table } 1 \\
\text { ARIMA and transfer function forecasts }\end{array}$} \\
\hline actual data & $\begin{array}{c}\text { forecasts of ARIMA } \\
\text { model }\end{array}$ & $\begin{array}{c}\text { forecasts of transfer function } \\
\text { model }\end{array}$ \\
\hline 6.0515 & 6.0492 & 6.0528 \\
\hline 6.0515 & 6.0516 & 6.0536 \\
\hline 6.0565 & 6.0532 & 6.0542 \\
\hline 6.0643 & 6.0549 & 6.0546 \\
\hline 6.0955 & 6.0566 & 6.0550 \\
\hline 6.0770 & 6.0582 & 6.0554 \\
\hline 6.0671 & 6.0599 & 6.0558 \\
\hline 6.0671 & 6.0616 & 6.0562 \\
\hline 6.0918 & 6.0633 & 6.0565 \\
\hline 6.0918 & 6.0650 & 6.0568 \\
\hline 6.0890 & 6.0666 & 6.0572 \\
\hline 6.2218 & 6.0683 & 6.0575 \\
\hline 6.2218 & 6.0700 & 6.0578 \\
\hline 6.1030 & 6.0717 & 6.0582 \\
\hline 6.0946 & 6.0733 & 6.0585 \\
\hline 6.0946 & 6.0750 & 6.0588 \\
\hline 6.0946 & 6.0767 & 6.0591 \\
\hline 6.1455 & 6.0784 & 6.0595 \\
\hline 6.1335 & 6.0801 & 6.0598 \\
\hline 6.1597 & 6.0817 & 6.0601 \\
\hline 6.1434 & 6.0834 & 6.0605 \\
\hline 6.2128 & 6.0851 & 6.0608 \\
\hline 6.2128 & 6.0868 & 6.0611 \\
\hline 6.1703 & 6.0885 & 6.0614 \\
\hline
\end{tabular}

From table 1, it is immediately evident that the transfer function forecasts better track the data as compared to the ARIMA forecasts, since it has smaller standard error (for example: the standard error for the first forecast of ARIMA model is 0.0193; whereas the standard error for the first forecast of transfer function model is (0.0179). The better transfer function forecasting performance occurs because, the auxiliary information enables the model to better anticipate the movement of Dinar series. 


\section{Summary}

In this application, a single equation transfer function is used to model exchange rate data for the US Dollar and the Jordanian Dinar against the Israeli Sheikl. Diagnostic checking for the transfer function is done. On the analysis, I found that the assumption of a unidirectional relationship may not be strictly true. Also, we noticed the importance of outlier detection and adjustment through the parameters significances and the moderate change in forecasted values. I come up with the conclusion that the transfer function forecasts better track the data as compared to the ARIMA forecasts. In this study, I added new empirical evidence on the importance of transfer function modeling that is forward - looking. It will capture both the immediate and longer term effects of intervention. This paper added a considerable methodology for the treatment of time series modeling in the presence of outliers. This methodology is considered a very important tool; it leads to evaluate the instant and dynamic effects in long term and for avoiding future economic shocks.

\section{Reference}

1. Box, G. E. P., And Jenkins, G. M., "Time Series Analysis: Forecasting And Control", San Francisco: Holden Day, 1970.

2. Box, G. E. P., And Tiao, G. C., "Intervention Analysis With Application To Economic And Environmental Problems", Journal Of The American Statistical Association ,70, 70-79, 1975.

3. Liu, L.-M., Hudak, G. B., "Forecasting And Time Series Analysis Using The SCA Statistical System", Vol. 1, 2, Dekalb, IL: Scientific Computing Associates, 19922000. 